\title{
A Novel Steel-Concrete Composite Flooring System: Development and Preliminary Experimental Investigation
}

\author{
Danilo Di Giacinto1, Daniele Losanno², Eugenio Ruocco ${ }^{1}$, Luigi Grassia ${ }^{1}$ \\ ${ }^{1}$ School of Polytechnics and of the Basic Sciences, University of Campania Luigi Vanvitelli \\ Via Roma 9, 81031 Aversa, Italy \\ danilo.digiacinto@unicampania.it; eugenio.ruocco@unicampania.it; luigi.grassia@unicampania.it \\ ${ }^{2}$ Department of Structures for Engineering and Architecture, University of Naples Federico II \\ Via Claudio 21, 80125, Naples, Italy \\ daniele.losanno@unina.it
}

\begin{abstract}
A new steel-concrete composite system is herein proposed to achieve a stronger, more ductile, and more economical flooring solution. The system consists of a smooth cold-formed steel profile fully embedded into a concrete pouring; Expanded Polystyrene (EPS) or hollow blocks are interposed between the steel profiles in order to lighten the slab weight. The system relies on particular shape and web holes only to achieve vertical interlocking and bonding resistance between concrete and cold-formed profile. The profile's shape has been properly designed through a multi-objective optimization process considering flexural performance, selfsupporting capacity, manufacturability, ease of installation, and compatibility with existing technologies. An experimental testing campaign on full-scale specimens has been carried out to investigate the flexural capacity of the system up to failure.
\end{abstract}

Keywords: Cold-Formed Steel; Steel-Concrete Composite Flooring; Composite Structures Plastic Limit Analysis; Experimental Investigation.

\section{Introduction}

Within the construction industry, the usage of concrete-steel composite slabs and beams is steadily increasing due to the speed of construction and a general cost reduction that can be achieved.

Current construction methods in Italy are based on a Prestressed Concrete T-beams (concrete joists) System (PCS) with hollow bricks or ESP blocks to provide a simple and economical suspended flooring system for most types of housing and low-rise buildings. (See Fig. 1). Joists are usually made with high strength concrete (e.g. 40MPa compressive strength) prestressed by means of twisted wires having a minimum tensile strength of $1670 \mathrm{MPa}$.
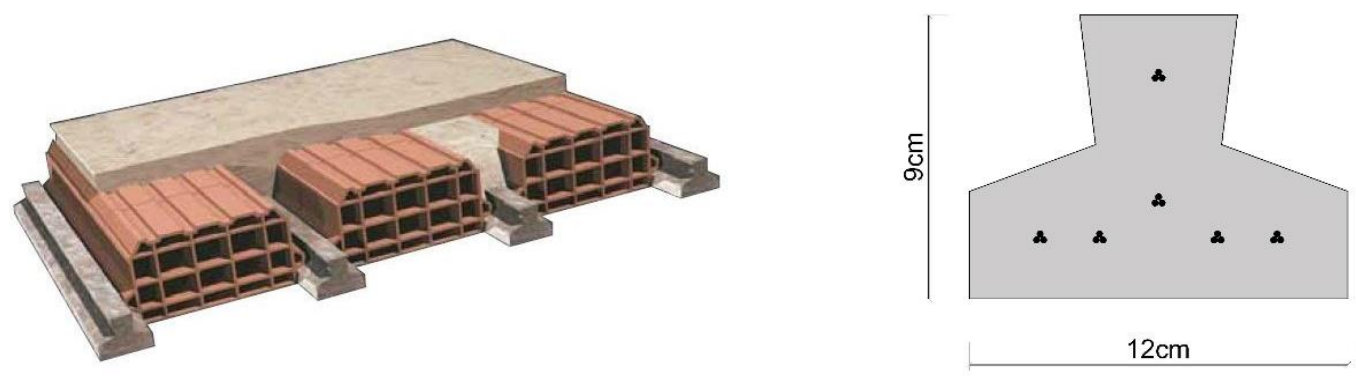

Fig. 1: Lightened ribbed concrete slab with precast joists.

Typical cross-sectional dimensions are $9 \mathrm{~cm}$ (height) and $12 \mathrm{~cm}$ (width) while relative spacing varies from $50 \mathrm{~cm}$ to $62 \mathrm{~cm}$. 
Floor strength depends on the joist (type and spacing) and the concrete slab (strength and thickness). A coupled assembling (adjacent joists) can be used to obtain stronger and stiffer slabs.

Manufacturers provide span vs load design charts for the selection of the most suitable combination of these variables. The total depth of the slab is also a function of the height of the lightening elements. Flexural capacity under service loads varies from about $8 \mathrm{kNm}$ for a $16 \mathrm{~cm}$-depth slab (including a $4 \mathrm{~cm}$-concrete topping) to $115 \mathrm{kNm}$ for a $42 \mathrm{~cm}$-depth slab (including a $6 \mathrm{~cm}$-concrete topping) [1]. This data refer to a $\mathrm{C} 25 / 30$ concrete casting (25MPa at 28 days).

The use of encased composite beams is constantly increasing due to benefits for the whole structures, such as overall self-weight reduction (lighter slabs permit to design smaller beams, columns, and foundations), least amount of concrete, and reduced construction time [2][3]. A preliminary assessment of the technology under study (Cold-Formed System) in comparison with the classical PCS is developed in the following.

\section{System description}

The system herein presented consists of Cold-Formed Steel (CFS) profiles spaced by lightening elements (e.g. EPS or hollow clay blocks), as shown in Fig. 2. These elements act both as permanent formwork for obtaining a ribbed slab and as thermal and acoustic insulation. The cold-formed steel profiles are manufactured from a $1.2 \mathrm{~mm}$ thick metal sheet through a roll bending process. As a main feature of the proposed technology, the steel shims are completely smooth in order to reduce the manufacturing cost. In addition to this, no fasteners are provided at a later step. A number of $60 \mathrm{~mm}$-diameter, $200 \mathrm{~mm}$-spacing holes are drilled on the vertical webs of the metal sheet prior to its bending. Since the bonding mechanism only relies on the smooth steel-concrete interface, these holes and the shape of the profile itself provide vertical interlocking and horizontal shear resistance between the steel element and the concrete slab. In this way, the two materials - concrete and steel - act together as a composite to create a stiffer, lighter and less expensive element until the bonding strength is reached. A wire steel mesh is embedded in the slab concrete to provide load distribution and avoid cracks due to shrinkage. Shape and dimensions of the Cold-Formed Profile (CFP) are shown in Fig. 3. It must be noted that developments on steel profile optimization have been also involved in earthquake engineering [4].

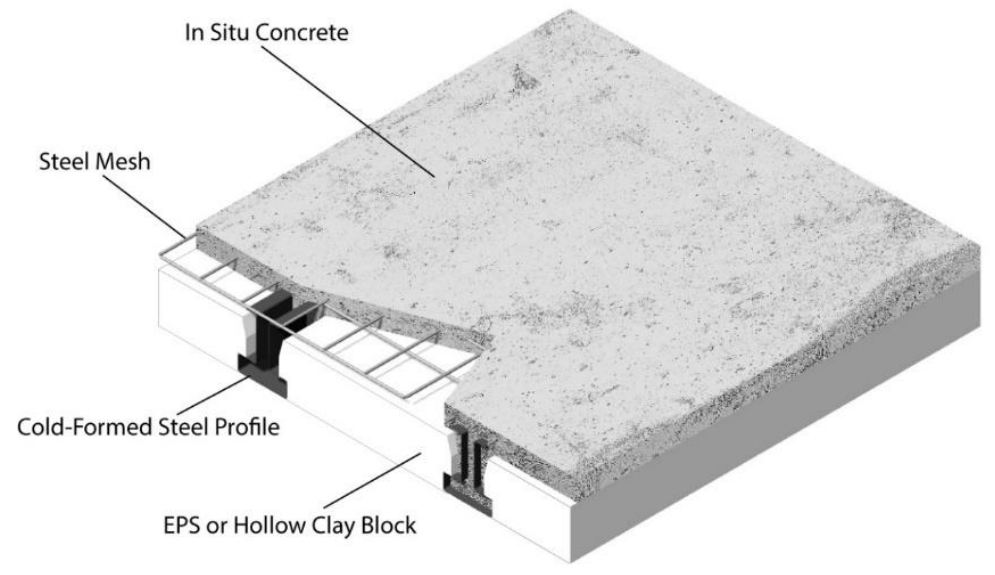

Fig. 2: The Steel-Concrete Composite Flooring System presented in this paper.

The proposed CFP has been obtained through a multi-criteria process that took into account the objectives described below:

1) Flexural capacity: considering a common span of $5 \mathrm{~m}$ (column-column distance for housing project), the flexural demand of the CFS has been set equal to $30 \mathrm{kNm}$ for a $1 \mathrm{~m}$-width slab under service loads with the corresponding mid-span deflection not exceeding the Eurocode limit [4], i.e. span length/500.

2) Self-Supporting capacity at the construction stage: the bare CFP has to carry the entire load due to fresh concrete pouring, lightening elements, wire mesh, construction live load and self-weight. Typical failure mechanism in this 
stage are related to lateral-torsional buckling. Recent works on the buckling behaviour of isotropic plates have been carried out taking into account the effect of transverse shear deformation [5].

3) Manufacturability: the CFP has to be produced by a standard rolling process with low residual stress and without any additional process for improving bonding.

4) Ease of installation: two workers have to be able to assemble the system without using heavy lifting devices.

5) Compatibility with existing technologies: this can be achieved reassembling concrete t-joist shape that allows juxtaposing lightening elements within the joists spacing.

\subsection{Specimens}

Four full-scale (\# 2 160mm-depth; \#2 170-mm depth) specimens for two single steel joist geometry (width $500 \mathrm{~mm}$ ) with $3 \mathrm{~m}$ span have been manufactured using steel grade S355 (characteristic yield stress of steel $\mathrm{f}_{\mathrm{yk}}=355$ $\mathrm{MPa}$, ) and a ready-to-use concrete mix in order to minimize factors such as moisture and dust content in the aggregate. Steel wire mesh of $\emptyset 6 / 150 \times 150 \mathrm{~mm}$ has been used for distributing load and avoiding shrinkage cracking.

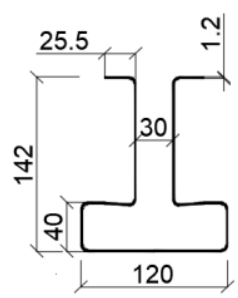

section

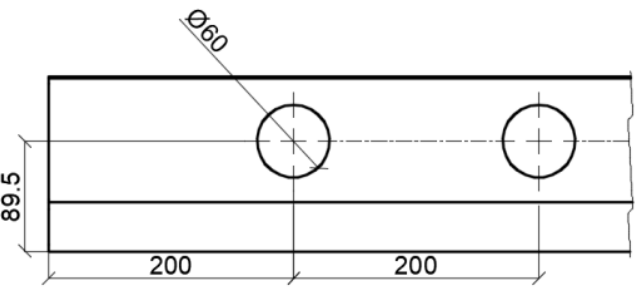

lateral view

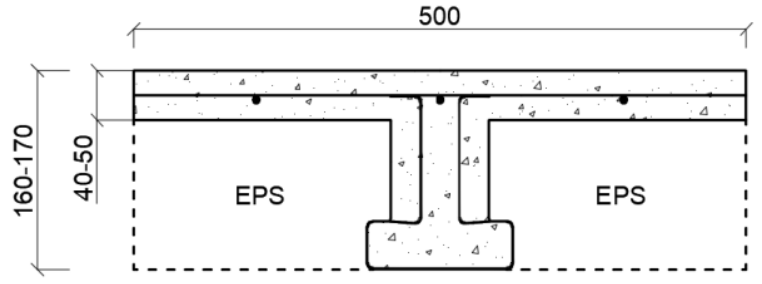

(b)

Fig. 3: (a) CFP geometry; (b) CFS specimens.

The ready-to-use concrete is produced by VAGA (Betonfluid) using 42.5R Portland cement, 0/8 siliceous aggregate, and acrylic superplasticizer in order to obtain class SF2 Self-Compacting concrete with a 0.45 water-cement ratio. The manufacturer data sheet claims a $40 \mathrm{MPa}$ compressive strenght at 28 days confirmed by testing.
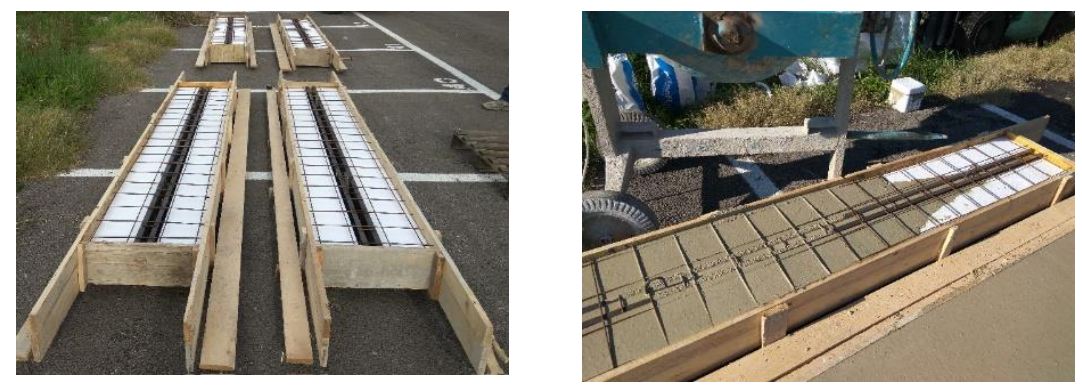

Fig. 4: Specimen formworks and casting.

\subsection{Analytical assessment of flexural capacity}

The flexural capacity of the single joist composite section has been calculated throughout a plastic analysis based on the following assumption in addition to design mechanical values for both steel and concrete:

1) Concrete resisting compressive stress only;

2) Rectangular stress block $(0.85 \mathrm{fc}$, where $\mathrm{fc}$ is the compressive strength) for compressive stress distribution within the concrete;

3) Yielding (fy) compressive/tensile stress of steel components. 


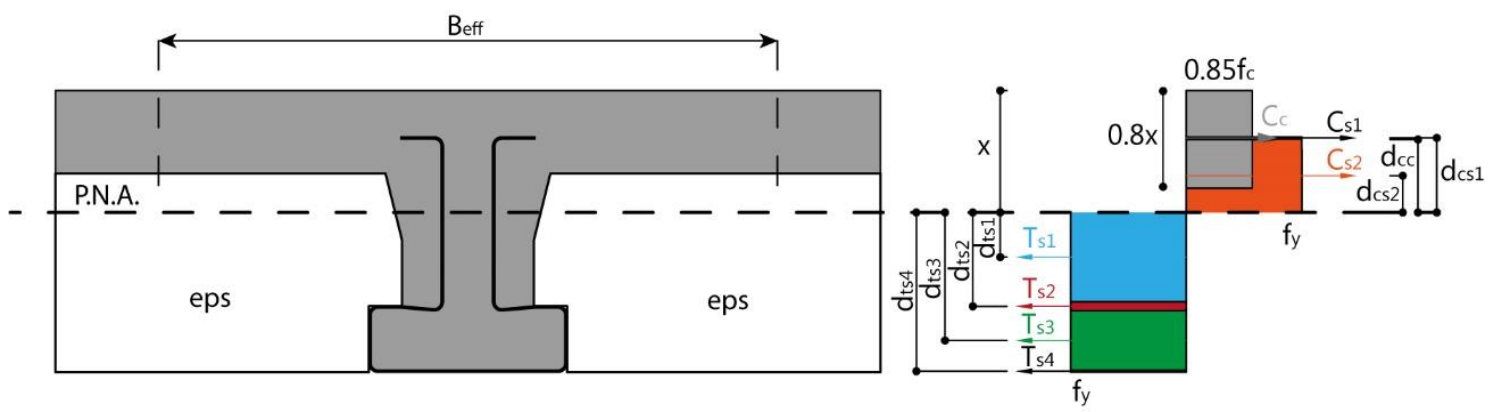

Fig. 5: Stress Distribution of the Composite Beam

The equilibrium of the total Compressive force $\mathrm{C}$ and the total Tensile force $\mathrm{T}$ allows calculating the position of the Plastic Neutral Axis (P.N.A.) [6][7][8]. The latter depends on the materials strength and the geometrical properties of the composite section.

If the P.N.A. due to positive moment is located within the web of the concrete slab, as shown in Fig. 1, the total compressive and tensile force may be obtained by summing up the contribution of each homogeneous part, see Eqs. (1) (2)

$$
\begin{gathered}
\mathrm{C}=\mathrm{C}_{\mathrm{c}}+\mathrm{C}_{\mathrm{g} 1}+\mathrm{C}_{\mathrm{g} 2} \\
\mathrm{~T}=\mathrm{T}_{\mathrm{g} 1}+\mathrm{T}_{\mathrm{g} 2}+\mathrm{T}_{\mathrm{g} 3}+\mathrm{T}_{\mathrm{g} 4}
\end{gathered}
$$

Where

\section{$\mathrm{C}_{\mathrm{c}}$ is the compressive force in the concrete}

Each $\mathrm{C}_{\mathrm{si}}$ represents the contribute of a steel portion in compression (for instance, the upper flanges) and $\mathrm{T}_{\mathrm{si}}$ is the contribute of a steel portion in tension (for instance, the bottom flange).

The depth $x$ of the P.N.A. easily come out from the equilibrium equation (3)

$$
\mathrm{C}=\mathrm{T}
$$

which is linear because $x$ appears just in the contribute due to the concrete.

Therefore, the flexural capacity Mrd of the composite section can be calculated as follows:

$$
M_{r d}=\mathrm{C}_{\mathrm{c}} d_{c c}+\mathrm{C}_{\mathrm{s} 1} d_{c s 1}+\mathrm{C}_{\mathrm{s} 2} d_{c s 2}+\mathrm{T}_{s 1} d_{t s 1}+\mathrm{T}_{\mathrm{s} 2} d_{t s 2}+\mathrm{T}_{s 3} d_{t s 3}+\mathrm{T}_{s 4} d_{t s 4}
$$

Where

$\mathrm{d}_{\mathrm{cc}}$ is the distance between Cc and the P.N.A.

$\mathrm{d}_{\mathrm{csi}}$ represents the distance between $\mathrm{C}_{\mathrm{si}}$ and the P.N.A.

and $\mathrm{d}_{\mathrm{tsi}}$ represents the distance between $\mathrm{T}_{\mathrm{si}}$ and the P.N.A.

It is worth noting that the Effective Width $B_{\text {eff }}$ is equal to span/8 [10].

According to this procedure, the flexural strength is equal to $20 \mathrm{kNm}$ and $22 \mathrm{kNm}$ for the $160 \mathrm{~mm}$-depth and the 170mm-depth specimen, respectively.

\section{Testing}

A testing experimental campaign has been carried out in order to investigate the flexural capacity of the CFS. A fourpoint bending test has been performed in order to clearly detect the failure mechanics (bonding/flexure), assumed that the shear strength of the CFP is adequate. A stiff I-Beam (HEA300) is adopted to split the total force into two points $500 \mathrm{~mm}$ distant with a clear span of $2.50 \mathrm{~m}$ between external supports (See Fig. 6). 


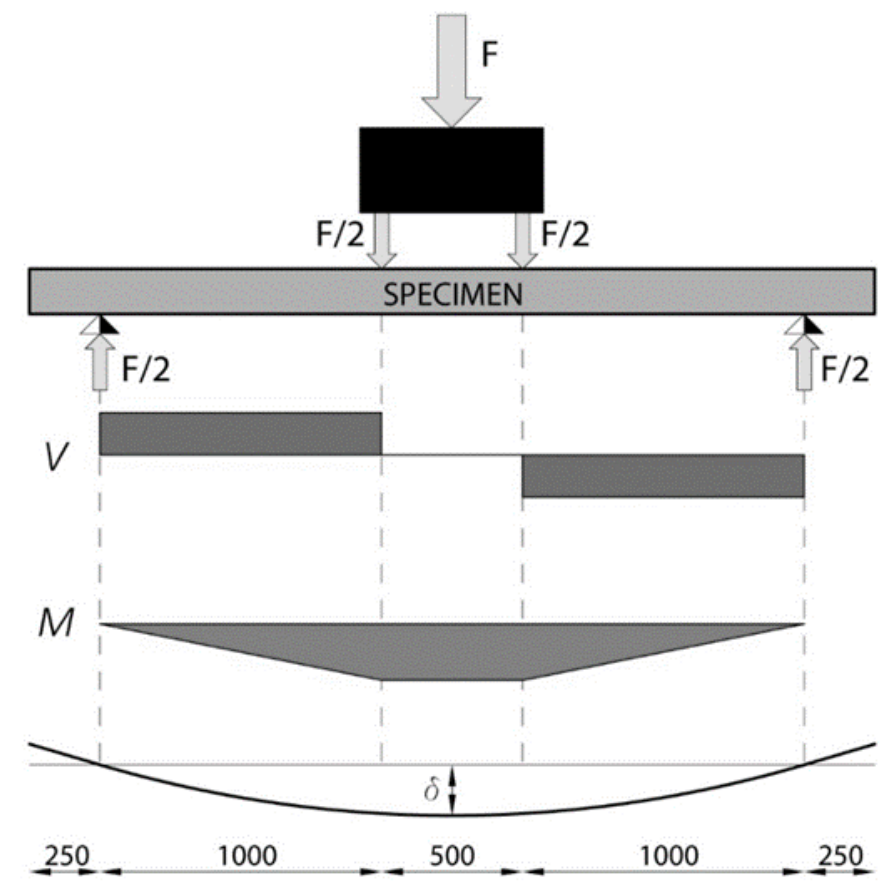

Fig. 6: four-point flexural test scheme (dimension in $\mathrm{mm}$ ).

\subsection{Loading and measurement method}

Fig. 7 shows the test set up. The specimens have been reacted by a relatively rigid loading frame that minimizes the soil reaction and avoids its uplift. The load has been increasingly applied by means of a $250 \mathrm{kN}$ capacity cylindrical hydraulic jack ENERPAC RCH $306\left(\mathrm{~A}=4660 \mathrm{~m}^{2}\right)$ using a manual pump and a digital manometer to directly measure the pressure (accuracy \pm 0.1 bar). This Loading Force $F$ was applied on a very stiff spreader I-beam that splits it into two concentrated loads F/2. A 500kN load cell placed between the hydraulic jack and the spreader has been used to measure the load. A first load/unload cycle has been performed to stabilize the system and avoid rigid translation at the supports. Then, following a $5 \mathrm{kN}$ stepped loading protocol the specimen has been led to failure, i.e. condition when the load remains constant. After reaching the maximum load, this has been kept constant for measuring displacements in the plastic field and then unloaded.

In order to measure displacements, six micrometer dial gauges (SAMA Tools mod. Jewelwd, 50/0.01mm) were installed on the upper side of the specimen according to the scheme in Fig. 8. A relative displacement value $\delta$ between the average middle and supports' measures have been considered as the representative Mid-Span Deflection in the results. 


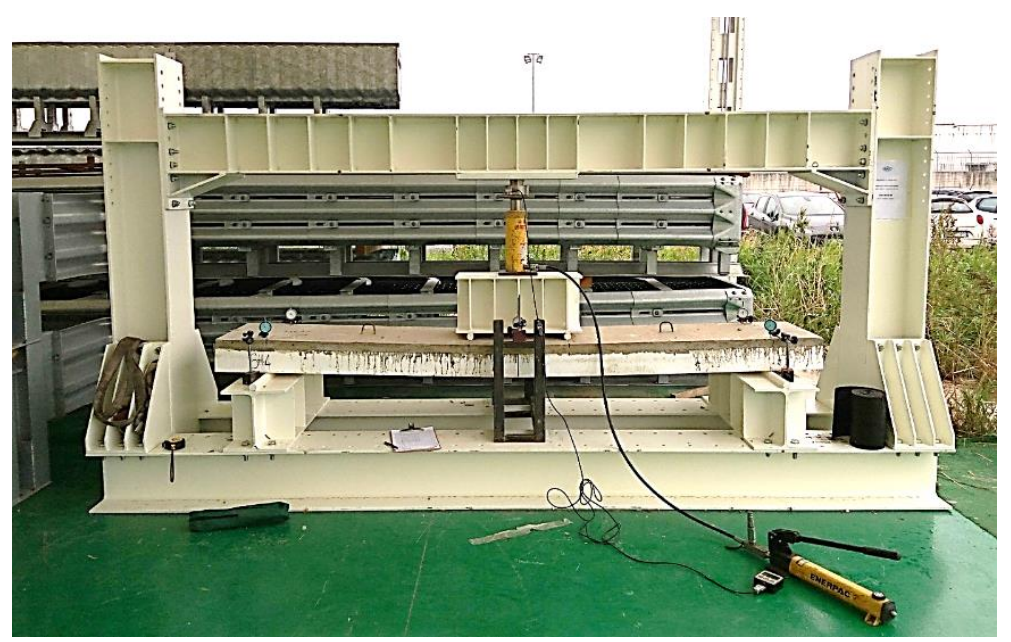

Fig. 7: test set up.

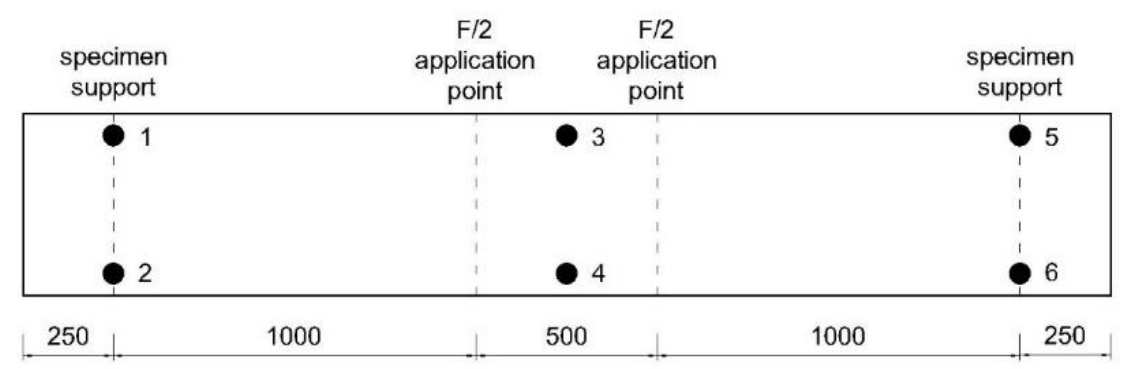

Top view

Fig. 8: scheme showing the micrometers positions and the application points of the loads.

\subsection{Test Results}

The results are shown in terms of Applied Load F - Mid-span Deflection $\delta$ in Fig. 9. Dashed lines represent load/unload behavior. A vertical straight line is also representing the serviceability deflection limit. 


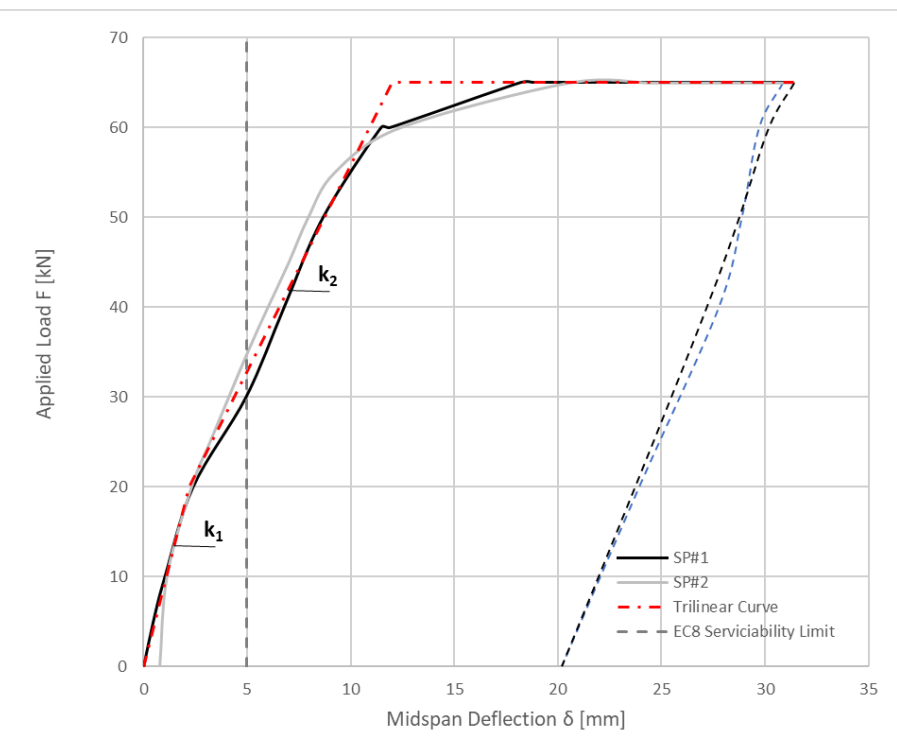

(a)

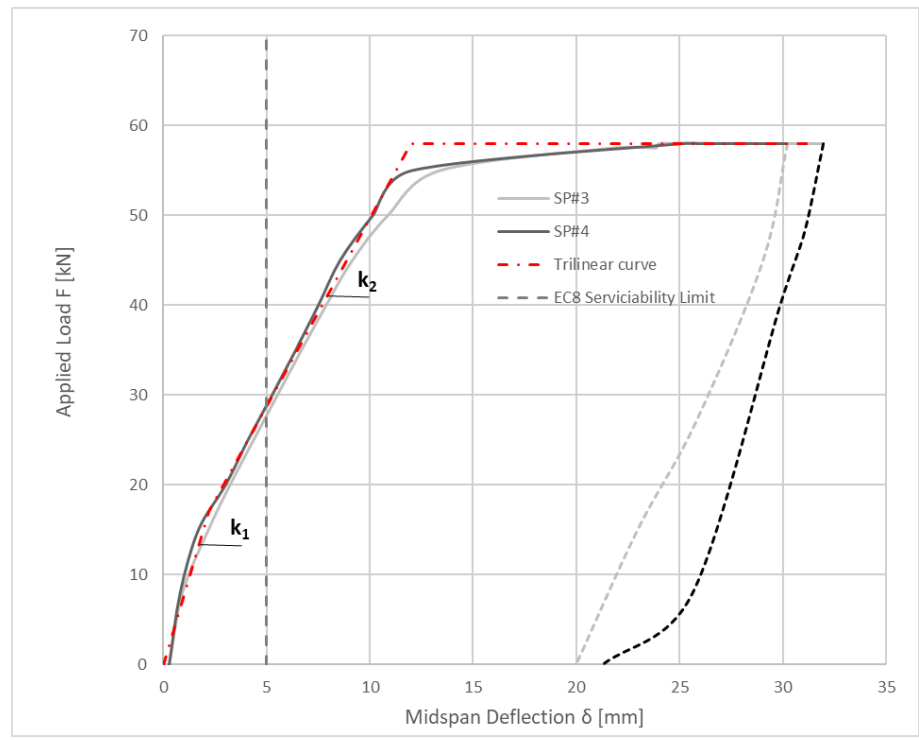

(b)

Fig. 9: Applied Load F - Midspan Deflection $\delta$ curves: (a) h=170mm, (b) h=160mm.

Experimental behavior of the four specimens is highly non-linear. The load $\mathrm{F}$ corresponding to the EC deflection limit (free span length $/ 500=5 \mathrm{~mm})$ resulted within the range $30 \mathrm{kN}(160 \mathrm{~mm}$-depth) and $35 \mathrm{kN}(170 \mathrm{~mm}$ depth). Thus, the corresponding flexural capacity of the single joist beam is about $15 \mathrm{kNm}$ and $17.5 \mathrm{kNm}$ for the for the $160 \mathrm{~mm}$ and $170 \mathrm{~mm}$-depth composite beam, respectively. Corresponding capacity for a $1 \mathrm{~m}$-width strip of composite slab would be $30 \mathrm{kNm}(160 \mathrm{~mm})$ and $35 \mathrm{kNm}(170 \mathrm{~mm})$. This experimentally confirmed the results of the multi-criteria optimization process in terms of flexural capacity to be compared with a classical PCS having the same capacity. It must be noted that, in order to obtain the same performance, the CFS provided to be about $50 \%$ lighter and $20 \div 30 \%$ cheaper than corresponding PCS.

The maximum recorded load was $65 \mathrm{kN}$ for specimens \#1-2 (170mm-depth) and $58 \mathrm{kN}$ for specimens \#3-4 (160mm-depth). A tri-liniear elastoplastic model was proposed to model the experimental response. A softer secondary branch $\left(\mathrm{k}_{2}\right)$ yields after concrete cracking $\left(\mathrm{k}_{1}\right)$ at a force level between 15 and $20 \mathrm{kN}$, with a ratio $\mathrm{k}_{2} / \mathrm{k}_{1}$ very close to 0.5 .

It is worth noting that specimens of the same width showed an identical behavior confirming the reliability of the system. Since a relative ductile mechanism was observed, it was necessary to investigate if due to flexural rather than bonding failure. Once the EPS lightening elements were removed, the visual inspection of the cracking pattern confirmed that neither concrete slab was cracked due to compression, nor the bottom flange was significantly yielded due to tension. This led to assume a bonding failure mechanism in the regions of the beam that are shear dominated. Even if the prototypes under study satisfactorily matched the design goal under service load, ongoing research is being developed to analyse the bonding mechanism and ultimate flexural capacity of the proposed CFS. 


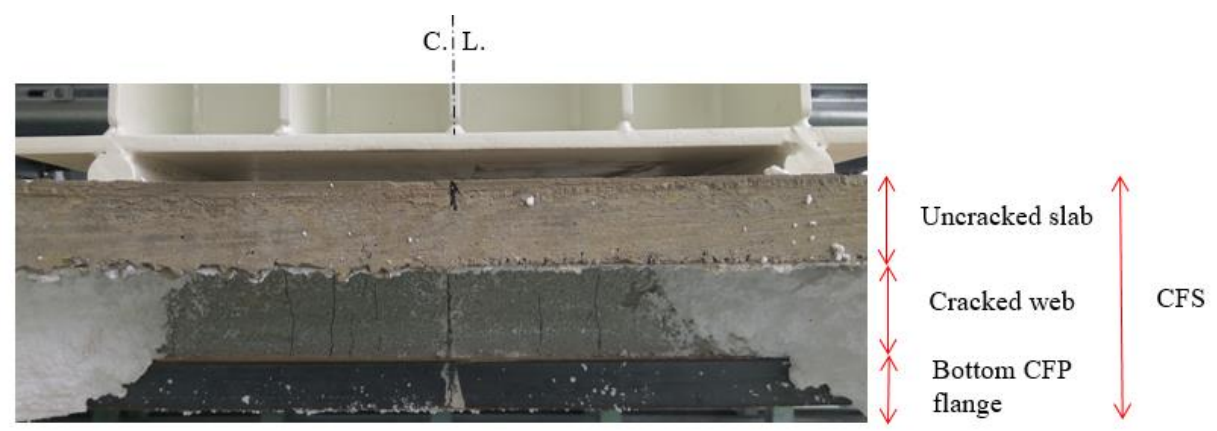

Fig. 10: Lateral view of Specimen \#1 after test in middle span.

\section{Conclusion}

This paper showed the development and the preliminary investigation of a novel cold formed composite flooring system. The idea is to replace the heavy and conventional ribbed concrete slab with precast joists with a lighter, cheaper and stronger flooring system obtained by combining a cold formed and smooth metallic sheet properly shaped with a concrete slab. The need to manufacture light and simple profile with neither impressed stamp nor welded fasteners provides a main problem of bonding at the concrete-steel interface. Preliminary evaluations led the authors to a special inverted "omega" shape and additional holes along the web in order to reduce the bonding stress and improve the interlocking action, respectively. A preliminary experimental campaign demonstrated a satisfactory flexural behaviour of the specimens under service loads. The loading process has been stopped due to bonding failure close to supports since neither cracking of the compressed slab nor significant plastic deformation of the steel profile were observed in the middle span. Further experimental investigation and analytical assessment will be developed in order to demonstrate the competitiveness of the suggested system and deepen the study of the bonding mechanism and ultimate flexural capacity.

\section{Acknowledgements}

The present work is part of the MISE (Ministero Italiano dello Sviluppo Economico) funded project n. PONA15/2179/00/X17 "Development of Innovative Structural Concrete Systems" (Sviluppo di sistemi innovativi portanti in calcestruzzo armato). The authors are grateful for the support received from Industry AMS for the supply of the specimens and the equipment discussed in this work.

\section{References}

[1] Fornaci Briziarelli Marsciano, Pretensioned Concrete Joist Technical data Sheet [Online]. Available: http://www.briziarelli.com/sch3d3/solaio\%20precompresso.pdf

[2] S. De Nardin and A. El Debs, "Composite connections in slim-floor system: An experimental study," Journal of Constructional Steel Research, Elsevier, 2012.

[3] G. Abdel-Sayed, "Composite Cold-formed Steel-concrete Structural System," $6^{\text {th }}$ International Specialty Conference on Cold-Formed Steel Structures, Rolla (MO), US, 1982, Paper 2.

[4] I. Nuzzo, D. Losanno, N. Caterino, G. Serino, L. M. Bozzo, "Experimental and analytical characterization of steel shear links for seismic energy dissipation," Engineering Structures, vol. 172, pp. 405-418, 2018.

[5] E. Ruocco, V. Mallardo, V. Minutolo, D. Di Giacinto, "Analytical solution for buckling of Mindlin plates subjected to arbitrary boundary conditions," Applied Mathematical Modelling, vol. 50, pp. 497-508, 2017.

[6] T. Limazie, S. Chen, "Numerical procedure for nonlinear behavior analysis of composite slim floor beams," Journal of Constructional Steel Research, Elsevier, 2015.

[7] J. W. Rackham, S. J. Hicks, and G. M. Newman, "Design of Asymmetric Slimflor Beams with Precast Concrete Slabs" The Steel Construction Institute, Ascot, UK, 2006.

[8] V. Kvočák, V. Kožlejová, and M. Karmazínová, "Verification of the Behavior of Deck Bridges with Encased Filler Beams," International Journal of Systems Applications, Engineering \& Development, Volume 6, Issue 1, pp. 163-170, 2012.

[9] BS EN 1990 Eurocode 0: Basis of Structural Design, Annex A1. 
[10] BS EN 1994:1-1 Eurocode 4: Design of composite steel and concrete structures - Part 1-1: General rules and rules for buildings.

[11] BS EN 1998-1 Eurocode 8: Design of structures for earthquake resistance-Part 1: General rules, seismic actions and rules for buildings. 